\title{
Uma análise da decisão judicial sobre "a exigência de diploma de curso superior para o exercício da profissão de jornalista" (RE 511.961/2009) à luz do Direito Humano e Fundamental à Liberdade de Expressão e da Teoria do Controle de Convencionalidade
}

\author{
An analysis of the judicial decision on "the requirement of a \\ diploma for the exercise of the journalist profession" (re \\ 511.961/2009) in the light of the Fundamental and Human Right to \\ Freedom of Expression and the Theory of Conventionality Control
}

Mariana Zonari ${ }^{1}$

\section{Lucas Ernesto Gomes Cavalcante ${ }^{2}$}

\begin{abstract}
Resumo: Com a impressionante evolução dos direitos humanos na última década, a ideia sagrada de soberania estatal foi inteiramente superada, fato que pode ser evidenciado pela crescente adesão dos Estados a mecanismos judiciais internacionais, submetendo-os à jurisdição internacional e, paralelamente, pelo progressivo condicionamento do direito interno pelas normas internacionais de direitos humanos. Nesse sentido, propõe-se neste trabalho realizar uma análise da decisão judicial sobre "a exigência de diploma de curso superior para o exercício da profissão de jornalista" (RE 511.961/2009) à luz do direito humano e fundamental à liberdade de expressão e sob o prisma da teoria do controle de convencionalidade das leis.
\end{abstract}

Palavras-chave: Controle de Convencionalidade. Direitos Humanos. Liberdade de Expressão.

\begin{abstract}
With the impressive evolution of human rights in the past decade, the sacred idea of state sovereignty has been fully overcome, which can be evidenced by the growing membership of States to international judicial mechanisms, submitting themselfs to international jurisdiction and, in parallel, the progressive conditioning of domestic law by the international human rights standards. In this sense, it is proposed in this paper to carry out a review of the court decision on "the demand for college degree for the exercise of journalism" (RE 511,961 / 2009) in the light of
\end{abstract}

\footnotetext{
1 Mestre em Direito Constitucional pela Universidade de Fortaleza (UNIFOR). PósGraduada em Direito Empresarial pela Universidade de Fortaleza (UNIFOR). Graduada em Direito pela Universidade de Fortaleza (UNIFOR). Bolsista da Fundação Cearense de Apoio ao Desenvolvimento Científico e Tecnológico (FUNCAP). Advogada.

2 Mestrando em Direito (Direito e Desenvolvimento) pela Universidade Federal do Ceará. Especialização em Direito Tributário pela Universidade Cândido Mendes (UCAM). Bacharelado em Direito pelo Centro Universitário Christus - UNICHRISTUS. Advogado
} 
the human and fundamental right to freedom of expression and under the prism of the theory of conventionality control of laws.

Keywords: Conventionality Control. Freedom of Expression. Human Rights.

"Je ne suis pas d'accord avec ce que vous dites, mais je me battrai jusqu'au bout pour que vous puissiez le dire"

Voltaire

\section{Introdução}

Apesar de a noção de direitos inerentes à pessoa humana encontrar expressão, ao longo da história, anos antes e em diferentes locais, foi somente com a Declaração Universal de Direitos Humanos de 1948 que os direitos humanos foram devidamente formulados juridicamente no plano internacional (TRINDADE, 2003a) e a sua evolução, ao longo das últimas décadas, é impressionante.

Desde então, surgiram diversos tratados e convenções internacionais objetivando a proteção indistinta dos direitos dos indivíduos, bem como diversos desses direitos foram internalizados nos âmbitos estatais, passando a se tornarem direitos fundamentais ${ }^{3}$. Felizmente, em compatibilização com o desenvolvimento dos direitos humanos, a visão de que o direito internacional está sujeito à vontade arbitrária dos Estados ou, ainda, à sagrada soberania estatal se encontra hoje inteiramente superada (TRINDADE, 2012).

O maior retrato da referida evolução e internacionalização dos direitos humanos é a crescente adesão de Estados a mecanismos internacionais judiciais ou quase-judiciais (RAMOS, 2009), tais como - e, no âmbito deste trabalho, mais relevante - a Corte Interamericana de Direitos Humanos. Nesse sentido, diversos países passaram a aceitar e a se submeter à jurisdição internacional e, em paralelo, passaram a ter o seu

\footnotetext{
${ }^{3}$ Mais sobre a distinção entre direitos humanos e direitos fundamentais, bem como sobre a conceituação de direitos humanos fundamentais será vista a diante neste trabalho.
} 
direito interno condicionado por estas normas internacional de direitos humanos.

É tendo esse contexto como base que se propõe, neste artigo, o estudo da teoria do controle de convencionalidade das leis (MAZZUOLI, 2001). O objetivo geral aqui pretendido é realizar uma análise da decisão judicial sobre "a exigência de diploma de curso superior para o exercício da profissão de jornalista" (RE n. 511.961/2009) à luz do direito humano e fundamental à liberdade de expressão e sob o prisma da teoria do controle de convencionalidade das leis.

Para tanto, iniciar-se-á com algumas importantes e necessárias conceituações. Então, feitas essas considerações iniciais, passar-se-á ao estudo da origem histórica dos direitos fundamentais, realizando uma passagem do seu entendimento desde o Estado Liberal até o atual Estado Democrático de Direito.

Posteriormente, será feita uma análise da liberdade de expressão, aqui entendida como um direito humano fundamental. No capítulo seguinte, far-se-á um estudo detalhado da teoria do controle de convencionalidade das leis e, por fim, será realizada uma análise detalhada do julgamento do RE $\mathrm{n}$. $511.961 / 2009$ especialmente no que diz respeito à teoria do controle de convencionalidade e ao direito humano e fundamental à liberdade de expressão.

Metodologicamente, a pesquisa utilizada foi bibliográfica, através de analises, comparações e conclusões embasadas em trabalhos publicados e que abordam direta ou indiretamente o tema em análise, bem como análise jurisprudencial. No que tange à tipologia - utilização dos resultados, a presente pesquisa é pura, tendo como finalidade o aumento do conhecimento da pesquisadora, objetivando uma nova tomada de posição. A abordagem é qualitativa, de caráter exploratório e descritiva quanto aos objetivos. 


\section{A origem histórica dos Direitos Fundamentais: do Estado Liberal ao Estado Democrático de Direito}

Antes de se adentrar na temática deste tópico, é importante, para fins de rigor metodológico, fazer uma breve conceituação do que se entende, no âmbito da presente pesquisa, por direitos fundamentais e, consequentemente, a sua necessária diferenciação em relação aos chamados direitos humanos. Far-se-á também, e para este mesmo fim, a distinção entre direitos e garantias fundamentais.

Direitos humanos são aqueles inerentes à própria natureza humana, anteriores ao reconhecimento do direito positivo e de ordem universal, ou seja, válidos em todos os lugares, para todos os povos e em qualquer tempo. Isto é, os direitos humanos podem ser compreendidos como "[...] aqueles direitos fundamentais que o homem possui pelo fato de ser humano, por sua própria natureza e pela dignidade que a ela é inerente” (CORREIA, 2005, p. 99). ${ }^{4}$

Já os direitos fundamentais representam aqueles direitos que decorrem da ordem jurídica interna positivada (GARCIA, 2002) e têm como objetivo principal a defesa da dignidade humana em todas as duas dimensões. "São consequências no plano jurídico, principalmente constitucional, do desenvolvimento histórico, político e social dos direitos humanos, buscando aplicabilidade e proteção legal dos mesmos" (RUIZ, 2006, p. 138).

Ou seja, em termos sucintos, os direitos fundamentais são os direitos humanos positivados na ordem jurídica interna de um Estado. Não se confundem os direitos fundamentais com as garantias fundamentais, uma

\footnotetext{
4 A doutrina majoritária estabelece que existem cinco direitos humanos básicos (vida, liberdade, igualdade, intimidade e propriedade), fundamentados na dignidade da pessoa humana e dos quais decorrem todos os demais direitos humanos e fundamentais (LOPES, 2014). Contudo, Lopes (2016) esclarece que inexiste consenso sobre a vida (uma vez que a mesma seria um pressuposto de direito e não um direito em si mesmo), a intimidade (que estaria incluída na vida) e a propriedade (que, por ser decorrente do ter e não do ser, não seria considerado um direito inerente ao ser humano).
} 
vez que estas têm como objetivo único assegurar o gozo daqueles, funcionando como verdadeiros mecanismos de proteção dos direitos fundamentais (LOPES, 2001b, p. 41-45). Feitas essas necessárias conceituações iniciais, passar-se-á ao tema deste tópico.

O surgimento dos direitos fundamentais, resultado de um desenvolvimento histórico da relação entre homem e Estado, data do surgimento dos Estados Constitucionais, mais precisamente o Estado Liberal no século XIX. Contudo, apesar da emergência dos direitos fundamentais somente ser reconhecida a partir da origem do Estado Liberal, pode-se afirmar que a sua evolução histórica se iniciou bem antes disso.

Inicialmente, o poder estatal era considerado ilimitado, comumente fundamentado na crença absolutista de que o rei deveria exercer um poder soberano e independente dos demais órgãos de Estado. Data do século XIII mais precisamente do ano de 1215 - a primeira vez em que o Estado cedeu o seu poder totalitário em benefício dos homens. Tal fato ocorreu através da Carta Magna de 1215, que teve como principal objetivo a limitação do poder absoluto dos reis ingleses, especialmente no reconhecimento de que a vontade do governante estaria sujeita à lei.

De acordo com Lopes (2001, p. 174), apesar de não ser possível associar o nascimento dos direitos fundamentais a um único acontecimento notável - visto que a sua eclosão decorre de todo um processo histórico no qual os direitos fundamentais estão intimamente ligados à noção de dignidade humana que cada sociedade possui em cada momento, a doutrina tradicional classifica os direitos fundamentais em gerações ${ }^{5}$, de acordo com a época do seu surgimento.

\footnotetext{
${ }^{5}$ Neste ponto, é importante frisar que a terminologia gerações não é amplamente aceita por vários doutrinadores, os quais entendem que a mesma poderia passar a - falsa - impressão de que, conforme as gerações fossem evoluindo, iria ocorrer uma substituição de uma geração por outra (o que não se admite). Dessa forma, muitos preferem o termo dimensões para falar da evolução histórica dos direitos fundamentais. Entre eles Sarlet (2007), Cançado Trindade (2003a) e até mesmo Paulo Bonavides (DIMOULIS; MARTINS, 2007).
} 
Os direitos de primeira geração estão visceralmente conectados com a formação do Estado Liberal, com surgimento - como visto acima, pelo menos teórico - no século XVIII. Foram os primeiros direitos do homem a serem positivados e têm como característica comum o indivíduo como seu titular, uma vez que são considerados prerrogativas do mesmo em face aos abusos do Estado (LOPES, 2001).

Incluem-se nesta categoria, portanto, aqueles direitos que se referem às liberdades negativas clássicas, os quais enfatizam o princípio da liberdade e configuram os direitos civis e políticos. São os direitos de resistência, que enfatizam a separação entre a sociedade e o Estado. A título de exemplo, são os direitos à vida, à igualdade, à propriedade, à liberdade, etc. Em suma, “[...] os direitos fundamentais de primeira dimensão representam exatamente os direitos civis e políticos, que correspondem à fase inicial do constitucionalismo ocidental, mas que continuam a integrar os catálogos das Constituições atuais [...]” (BONAVIDES, 1997).

Em meio à expansão do modelo liberal clássico, o desenvolvimento industrial e o surgimento de uma nova classe de trabalhadores (proletariado), nascem os chamados direitos de segunda geração (LOPES, 2011). Também chamados de direitos sociais, os direitos fundamentais de segunda geração estão diretamente relacionados à Revolução Industrial, à Primeira Grande Guerra e à luta dessa nova classe do proletariado por direitos essenciais e básicos como alimentação, saúde e educação.

O surgimento desses tipos de direitos, verdadeiras liberdades positivas com o fim de assegurar o princípio da igualdade material entre os seres humanos, demonstram o processo de socialização do Estado, uma vez que constatam a necessidade de se proteger, além do indivíduo, a sociedade na qual o mesmo se encontra inserido (BONAVIDES, 1997). De acordo com Sarlet (2007, p. 50), “[...] os direitos de segunda dimensão podem ser considerados uma densificação do princípio da justiça social [...]”. Fazendo 
uma comparação entre os direitos de primeira e segunda geração, George Marmelstein (2008, p. 50) afirma que:

Os direitos de primeira geração tinham como finalidade, sobretudo, possibilitar a limitação do poder estatal e permitir a participação do povo nos negócios públicos. Já os direitos de segunda geração possuem um objetivo diferente. Eles impõem diretrizes, deveres e tarefas a serem realizadas pelo Estado, no intuito de possibilitar aos seres humanos melhores qualidade de vida e um nível de dignidade como pressuposto do próprio exercício da liberdade. Nessa acepção, os direitos fundamentais de segunda geração funcionam como uma alavanca ou uma catapulta capaz de proporcionar o desenvolvimento do ser humano, fornecendo-lhe as condições básicas para gozar, de forma efetiva, a tão necessária liberdade.

Já os direitos de terceira geração - também chamados de direitos de solidariedade, são aqueles constitucionalizados pelos Estados Democráticos de Direito, os quais representam o verdadeiro equilíbrio entre os Estados Liberais e Sociais (GUERRA FILHO, 1997). Com altíssimo teor de humanismo e universalidade, os direitos fundamentais de terceira geração visam proteger interesses de titularidade difusa (o gênero humano) em detrimento dos interesses de um determinado indivíduo, grupo ou Estado (BONAVIDES, 2006). De maneira bastante sistematizada, George Marmelstein, citando o jurista tcheco Karel Vasak, descreve (2008, p. 42):

[...] "as gerações - evolução - dos direitos fundamentais", da seguinte forma: a) primeira geração dos direitos seria a dos direitos civis e políticos, fundamentados na liberdade (liberté), que tiveram origem com as revoluções burguesas; b) a segunda geração, por sua vez, seria a dos direitos econômicos, sociais e culturais, baseados na igualdade (égalité), impulsionada pela Revolução Industrial e pelos problemas sociais por ela causados; c) por fim, a última geração seria a dos direitos de solidariedade, em especial o direito ao desenvolvimento, à paz e ao meio ambiente, coroando a tríade com a fraternidade (fraternité), que ganhou força após a Segunda Guerra Mundial, especialmente após a Declaração Universal dos Direitos Humanos, de 1948.

Feitas essas considerações iniciais - e necessárias - sobre o surgimento dos direitos fundamentais e levando em consideração que os mesmos foram sendo conquistados e consolidados ao decorrer de um longo processo histórico, faz-se necessário realizar uma breve análise histórica do 
direito humano fundamental à liberdade (aqui entendida como gênero, do qual o direito à liberdade de expressão é espécie), bem como verificar o status desse direito no atual Estado Democrático de Direito brasileiro.

\section{A Liberdade de Expressão como Direito Humano Fundamental}

Conforme delimitado anteriormente, considera-se, para fins de recorte e rigor metodológico da presente pesquisa, o direito à liberdade como um direito humano fundamental. Frise-se, direito humano pois a liberdade é inerente à própria natureza humana, de ordem universal e independente de qualquer tipo de positivação e direito fundamental visto que, na ordem jurídica brasileira, o direito à liberdade foi amplamente positivado como tal na Constituição Federal de 1988.

Ao considerarmos que a liberdade de expressão é uma das dimensões do direito humano fundamental à liberdade (MEYER-PFLUG, 2009), considera-se, também e pelos mesmos critérios, que a liberdade de expressão é, igualmente, um direito humano fundamental. Partindo dessas premissas, faz-se relevante uma breve análise histórica do direito à liberdade para, somente então, passar-se à investigação acerca do que prima facie se entende como o âmbito de incidência normativo da liberdade de expressão.

A liberdade está diretamente ligada à própria natureza humana, sendo anterior ao Estado, ao direito e até mesmo à existência da sociedade (MEYER-PFLUG, 2009). Foi o homem que, ao fazer a opção por viver em uma sociedade politicamente organizada, fez também a escolha de abrir mão de certos aspectos da sua liberdade individual.

$\mathrm{Na}$ Grécia antiga, a ideia de liberdade estava umbilicalmente vinculada à noção de política, uma vez que era somente através da política que o homem se afirmava como um ser livre (HELD, 1996). Diante dessa ótica, a liberdade era privilégio dos cidadãos atenienses que tinham o direito de participar das decisões políticas da polis, nomeadamente os homens e 
maiores de dezoito anos, sendo excluídas as mulheres, os escravos e os estrangeiros (GOYARD-FABRE, 2003).

Essa noção de liberdade foi sendo modificada no decorrer dos tempos e, na Idade Média, não mais significava a simples participação política, mas sim a não submissão aos poderes dos monarcas. No período de transição entre a Idade Média e a Idade Moderna, modifica-se o fundamento das leis, que passam da influência divina à racionalidade humana, fazendo nascer a ideia de Estado de Direito.

Conforme explicitado anteriormente, é nesse momento, do surgimento dos Estados Constitucionais, mais precisamente do Estado Liberal, que a liberdade, com nítido viés de direito de defesa, ganha destaque, passando a compor de forma positivada o importante rol dos direitos fundamentais. Anos depois com o Estado Social, pautado na preocupação não somente com a liberdade do indivíduo perante o Estado, a ideia de liberdade se modifica novamente, passando a ser entendida como um dever positivo do Estado de promover liberdade através do bem-estar social (SARLET, 2007).

No âmbito do atual Estado Democrático de Direito brasileiro, fruto do neoconstitucionalismo (BARCELLOS, 2006), no qual impera a lei e o equilíbrio entre o Estado Liberal abstencionista e o Estado Social intervencionista, a ideia de liberdade passa a ter um âmbito mais relevante e ultrapassando a noção que tinha anteriormente, concretizada na Constituição Federal de 1988 como cláusula pétrea - e portanto, irrevogável - (LOPES, 2001) e se dividindo em várias sub-liberdades (entre elas a liberdade de expressão).

A liberdade de expressão é um direito humano fundamental básico (alicerce de diversos outros direitos fundamentais) que, consagrado na Constituição Federal de 1988 em meio a uma ruptura histórica com o regime autoritário então vigente, constitui um dos pilares do Estado Democrático de Direito brasileiro, isto porque, indubitavelmente, a liberdade de expressão 
se encontra diretamente ligada ao grau de democracia de determinado Estado (MENDES, 2008).

A liberdade de expressão constitui o direito de cada indivíduo de manifestar seus pensamentos sem qualquer tipo de restrição por parte do Estado (MEYER-PFLUG, 2009). No mesmo sentido Horbach (2012, p. 220), para quem “[...] a liberdade de expressão representa o direito assistido a todos de manifestar seus pensamentos e convicções, sem qualquer intervenção estatal a priori”. Ainda, para Barroso (2004, p 18) a liberdade de expressão "[...] destina-se a tutelar o direito de externar ideias, opiniões, juízos de valor, em suma, qualquer manifestação do pensamento humano". Importante citar, também, o pensamento de Jónatas Machado (2002, p. 238), para quem a liberdade de expressão tem como objetivo “[...] a procura da verdade, da garantia de um mercado livre de ideias, a participação no processo de auto-determinação democrática, a proteção da diversidade de opiniões, a estabilidade social e a transformação pacífica da sociedade e a expressão da personalidade individual".

Importante frisar que, para os fins deste estudo, entende-se, conforme Stuart Mill (1978), que o pensamento e a expressão são praticamente equiparados. Isso porque é impossível se separar a liberdade de pensamento/sentimento/opinião da liberdade de expressão. $\mathrm{Na}$ mesma compreensão, Abigail Levin (2010) compreende que essa impossibilidade de separação dos dois tipos de liberdade reside no fato de que o homem só tem como formar, de modo pleno, a sua consciência e pensamento se puder expressá-los e, assim, compartilhá-los com os seus semelhantes. Nesse sentido, não basta assegurar ao indivíduo o direito de ter sua opinião, é fundamental que se tenha o direito de, livremente, expressar seu pensamento e, com isso, tentar convencer os demais e modificar a sociedade (MEYER-PFLUG, 2009).

Desta forma, percebe-se que a liberdade de expressão possui um caráter complexo pois, ao mesmo tempo que em que significa a liberdade de 


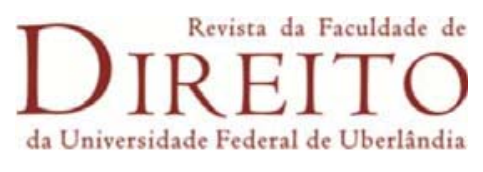

expressar seus pensamentos, significa, também, a liberdade para ter acesso e aprender sobre as opiniões dos demais membros da sociedade (GRIMM, 2009). Nesse mesmo sentido, Barroso (2004) entende que a liberdade de expressão, por seu "[...] caráter de inegável interesse público da livre circulação de ideias" e por facilitar o exercício de outras liberdades, possui uma posição preferencial ${ }^{6}$ em relação aos demais direitos fundamentais.

Isto posto, é relevante salientar que a liberdade de expressão não possui caráter absoluto, encontrando limites na própria Constituição (BARROSO, 2004), de modo que tal direito fundamental não é imune ao controle estatal, que tem o dever de agir sempre que houver risco de prejuízo à dignidade humana ou ao regime democrático (MENDES, 2008). Apesar de certas restrições - fundamentadas no próprio texto constitucional (MEYERPFLUG, 2009) - serem possíveis em determinados casos concretos, deve-se, de todo modo, proteger sempre o conteúdo essencial do direito ${ }^{7}$.

No âmbito internacional, o direito à liberdade de expressão sempre recebeu o seu devido destaque e proteção. Neste sentido, cita-se o artigo 11 da Declaração dos Direitos do Homem e do Cidadão, os artigos 18 e 19 da Declaração Universal dos Direitos Humanos, o artigo IV da Declaração Americana dos Direitos e Deveres do Homem, artigo 19 do Pacto Internacional sobre os Direitos Civis e Políticos e, especialmente relevante para este trabalho, o artigo 13 da Convenção Americana de Direitos Humanos (Pacto de São José da Costa Rica).

Questiona-se, neste momento, se estas normas de direito internacional podem (e caso sim, como podem) afetar o direito interno e, mais ainda, os precedentes jurisprudenciais domésticos. Feitas essas

\footnotetext{
${ }^{6}$ Barroso (2004) faz referência à doutrina norte-americana dos preferred rights, que confere a determinados direitos fundamentais posições de preferência em relação aos demais, pelo menos quando teórica e individualmente considerados, uma vez que, no caso concreto, frente a argumentos reais mais fortes e consistentes, essa preferência pode não prevalecer.

7 Deve-se respeitar, sempre, o conteúdo essencial dos direitos fundamentais. Isto é, o chamado limite dos limites. Constitui a proteção mínima do núcleo essencial de um direito fundamental, assim entendido como o âmbito de proteção mínimo, intocável, sem o qual o direito se desconfiguraria e deixaria de ser aquele direito (MENDES, 2008).
} 
considerações, sem nenhuma tentativa de exaurimento do tema, passar-se-á ao estudo da teoria do controle de convencionalidade.

\section{Da Teoria do Controle de Convencionalidade}

Para se estudar o tema da teoria do controle jurisdicional de convencionalidade das leis - vulgo: teoria do controle de convencionalidade, é condição sine qua non um estudo, ainda que sem o objetivo de aprofundar o assunto, do status hierárquico dos tratados de direitos humanos no direito brasileiro. Isso ocorre pois se adota, para os fins do presente trabalho, o conceito de controle de convencionalidade para designar exclusivamente a compatibilização vertical das leis internas com os tratados de direitos humanos em vigor no país, diferentemente da expressão controle de supralegalidade, utilizada para descrever a situação de compatibilização das leis internas com os tratados internacionais comuns (MAZZUOLI, 2011).

A Constituição Brasileira de 1988, de cunho marcadamente humanizado, representou a ruptura com o sistema vigente à época (ditatorial e autoritário) e um passo importante na redemocratização do Estado Brasileiro (TRINDADE, 2003b). Paralelamente a isso, a Constituição de 1988, além de eleger a dignidade da pessoa humana (artigo $1^{\circ}$, III) como fundamento do Estado Brasileiro e a prevalência dos direitos humanos (artigo $\left.4^{\mathrm{o}}, \mathrm{II}\right)^{8}$ como princípio pelo qual o país se regerá nas suas relações externas, também representou, por meio da adoção do parágrafo $2^{\circ}$ do artigo $5^{\text {o9 }}$, um gesto importante na intenção brasileira de abrir o seu ordenamento

\footnotetext{
8 Nesse sentido, Cançado Trindade (2003a, p. 434): "no presente domínio de proteção, não há mais pretensão de primazia do direito internacional ou do direito interno, como ocorria na polêmica clássica e superada entre monistas e dualistas. No presente contexto, a primazia é da norma mais favorável às vítimas, que melhor as proteja, seja ela norma de direito internacional ou de direito interno".

${ }^{9}$ Por extremamente relevante ao tema deste trabalho, transcreve-se, aqui, o parágrafo $2^{\circ}$ do artigo $5^{\circ}$ da Constituição Federal de 1988: "§ $2^{\circ}$ Os direitos e garantias expressos nesta Constituição não excluem outros decorrentes do regime e dos princípios por ela adotados, ou dos tratados internacionais em que a República Federativa do Brasil seja parte" (BRASIL, 1988).
} 
jurídico e compatibilizá-lo com o sistema internacional de proteção dos direitos humanos.

A partir do referido dispositivo constitucional (parágrafo $2^{\circ}$ do artigo $5^{\circ}$ ) e seguindo as tendências constitucionais contemporâneas, defende-se que os direitos e garantias individuais internacionalmente consagrados (notadamente aqueles trazidos ao direito interno por meio de tratados internacionais de direitos humanos devidamente ratificados pelo Brasil) possuem nível constitucional e aplicação imediata, passando a compor o bloco de constitucionalidade ${ }^{10}$ brasileiro ${ }^{11}$.

É importante salientar que existem sim entendimentos contrários a este posicionamento aqui defendido (incluindo nesse rol o entendimento do Supremo Tribunal Federal (STF), como se verá adiante). Contudo, os mesmos não podem prevalecer. Frise-se, por relevante, que o próprio autor da proposta do parágrafo $2^{\circ}$ do artigo $5^{\circ}$, Prof. Cançado Trindade (2003b, p. 622), entende que "Mediante este dispositivo constitucional, os direitos consagrados em tratados de direitos humanos em que o Brasil seja Parte incorporam-se ipso jure ao elenco dos direitos constitucionalmente consagrados". 12

Como dito anteriormente, o entendimento do STF, apesar de ter sofrido modificação com o passar dos anos, não coaduna com a tese da constitucionalidade. O STF, durante a vigência da Constituição de 1969, firmou entendimento de que os tratados internacionais (e aqui, independentemente da matéria sobre qual versarem) se incorporariam ao

\footnotetext{
${ }^{10}$ Não se abordará de forma aprofundada neste trabalho, por simples razão de necessidade de corte de metodológico, o tema de bloco de constitucionalidade com detalhes. Contudo, sem o objetivo de esgotar o conceito e apenas para fins de compreensão do texto, traz-se aqui o conceito de bloco de constitucionalidade de Ana Maria D'Ávila (2010, p. 45): bloco de constitucionalidade é "[...] o conjunto de normas que, junto com a constituição codificada de um Estado, formam um bloco normativo de nível constitucional".

${ }^{11}$ Este é o entendimento predominante de boa parte da doutrina nacional de peso. A saber: Cançado Trindade (2003b), Flávia Piovesan (2007), Valério Mazzuoli (2011), Ana Maria D’Ávila (2010), dentre outros.

$12 \mathrm{O} \S 2^{\circ}$ do artigo $5^{\circ}$ da Constituição Federal de 1988 resultou de proposta do Prof. Antônio Augusto Cançado Trindade na audiência pública de 29.04.1987 da Assembleia Nacional Constituinte à Subcomissão dos Direitos e Garantias Individuais (TRINDADE, 2003b).
} 


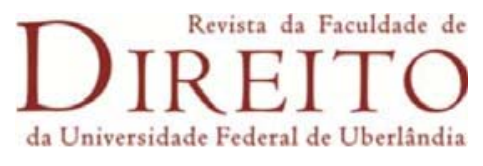

direito interno em nível de lei ordinária, podendo, nesse caso, serem revogados por lei posterior ou deixar de serem aplicados em favor de lei específica (MAUÉS, 2013) ${ }^{13}$.

Infelizmente, apesar da inclusão do $\S 2^{\circ}$ do artigo $5^{\circ}$ na Constituição Federal de 1988, o entendimento jurisprudencial - pelo menos inicial - do STF não foi alterado, uma vez que, no julgamento da ADIn 1.347 de 1995, a Corte Suprema confirmou o seu entendimento anterior de que os tratados internacionais estariam subordinados à Constituição e se situariam no mesmo plano de validade, eficácia e autoridade das leis ordinárias ${ }^{14}$. Sobre o assunto, Cançado Trindade (2003b, p. 624):

A tese da equiparação dos tratados de direitos humanos à legislação infraconstitucional - tal como ainda seguida por alguns setores em nossa prática judiciaria, não só representa um apego sem reflexão a uma postura anacrônica, já abandonada em vários países, mas também contraria o disposto no artigo $5(2)$ da Constituição Federal brasileira.

Com a promulgação da Emenda Constitucional de n. 45 de 2004, foi incluído o parágrafo $3^{\circ}$ ao artigo $5^{\circ 15}$ da Constituição ${ }^{16}$. Nesse sentido, houve

\footnotetext{
${ }^{13}$ Cite-se, a título de exemplo, o julgamento do RE 80.004 de 1977.

${ }^{14}$ No mesmo sentido o julgamento do HC n. 72.131 de 1995.

15 Art. 5, para. 3 da Constituição Federal de 1988: "Os tratados e convenções internacionais sobre direitos humanos que forem aprovados, em cada Casa do Congresso Nacional, em dois turnos, por três quintos dos votos dos respectivos membros, serão equivalentes às emendas constitucionais" (BRASIL, 1988).

${ }^{16}$ Interessante notar que, apesar de o $\S 3^{\circ}$ do artigo $5^{\circ}$ ter tido - pelo menos aparentemente um bom propósito, boa parte da doutrina entende que o dispositivo é incongruente e, além de não ter cessado com as polêmicas sobre o tema, teve papel no aumento das discussões, demonstrando um posicionamento brasileiro no sentido de se evadir dos seus compromissos de proteção ao ser humano. Segundo Cançado Trindade (2007, p. 209), falando sobre o referido dispositivo, esse "[...] retrocesso provinciano põe em risco a interrelação ou indivisibilidade dos direitos protegidos em nosso país (previstos nos tratados que o vinculam), ameaçando-os de fragmentação ou atomização, em favor dos excessos de um formalismo e hermetismo jurídicos eivados de obscurantismo. [...] Os triunfalistas da recente Emenda Constitucional 45/2004 não se dão conta de que, do prisma do direito internacional, um tratado ratificado por um Estado o vincula ipso jure, aplicando-se de imediato, quer tenha ele previamente obtido aprovação parlamentar por maioria simples ou qualificada. Tais providências de ordem interna - ou, ainda menos, de interna corporis são simples fatos do ponto de vista do ordenamento jurídico internacional, inteiramente irrelevantes. A responsabilidade internacional do Estado por violações comprovadas de direito humanos permanece intangível, independentemente dos malabarismos pseudojurídicos de certos publicistas".
} 
uma mudança no entendimento e todos os Ministros do STF passaram a compreender, sem exceção, que se deveria reconhecer às normas internacionais de proteção dos direitos humanos uma posição diferenciada no ordenamento jurídico interno (MAUÉS, 2013). Isso, contudo, não significou uma concordância sobre a polêmica do nível hierárquico desses tratados - pelo contrário.

Com a superação da tese da legalidade e com a falta de representatividade no STF da tese da supraconstitucionalidade (MELLO, 1999), a discussão ficou em torno de duas teses: i) a da constitucionalidade (acima explicitada) e ii) a da supralegalidade (de que os tratados de direitos humanos teriam um nível hierárquico superior às leis ordinárias, mas inferior à Constituição). Infelizmente, a tese da supralegalidade, capitaneada pelo Ministro Gilmar Mendes ${ }^{17}$, foi vencedora no STF por maioria de 5 votos a 4 (HC 87.585 e RE 466.343, ambos de 2008), sendo vencidos os votos dos Ministros Celso de Mello, Cezar Peluso, Eros Grau e da Ministra Ellen Gracie.

Dessa forma, em resumo, o posicionamento atual do STF é o de que os tratados internacionais de direitos humanos possuem status supralegal (a não ser que sejam aprovados segundo o rito do parágrafo $3^{\circ}$ do artigo $5^{\circ}$, quando passam a ser equivalentes a emendas constitucionais), enquanto os demais tratados internacionais ratificados pelo país têm nível de lei ordinária. Em contraposição a este pensamento, defende-se neste trabalho e o controle de convencionalidade será estudado tendo este prima como premissa - que os tratados internacionais comuns são os que possuem nível supralegal, enquanto os tratados internacionais de direitos humanos, independentemente da sua aprovação pelo rito do parágrafo $3^{\circ}$ do artigo $5^{\circ}$, possuem status materialmente constitucional e aqueles aprovados pelo

\footnotetext{
${ }_{17}$ Retomando a visão pioneira do Ministro Sepúlveda Pertence que, em seu voto no HC n. 79.785 de 2000, citou pela primeira vez no Brasil a tese da supralegalidade.
} 
supracitado rito são equivalentes a emenda constitucional e, portanto, material e formalmente constitucionais.

Ou seja, filiamo-nos à parte da doutrina que entende que os tratados internacionais que versam sobre direitos humanos são, sempre, materialmente constitucionais e, portanto, integram o bloco de constitucionalidade brasileiro. Nesse sentido, a única diferença entre os tratados de direito humanos anteriores à Emenda Constitucional 45/2004ou posteriores e não aprovados pelo rito do parágrafo $3^{\circ}$ do artigo $5^{\circ}-\mathrm{e}$ aqueles aprovados de acordo com o referido rito é que estes possuem, além do nível de materialmente constitucionais, o status de formalmente constitucionais. De acordo com Mazzuoli (2011) a principal distinção prática entre os tratados considerados materialmente constitucionais e aqueles considerados formal e materialmente constitucionais é que estes podem servir de paradigma de controle de convencionalidade difuso e concentrado, enquanto aqueles somente para controle difuso.

Ultrapassadas essas necessárias considerações sobre o status dos tratados de direitos humanos no âmbito do direito interno brasileiro, passarse-á ao estudo do controle de convencionalidade.

A expressão controle de convencionalidade tem sua origem datada na década de 70 na França no âmbito do julgamento de no 74-54 DC (de 15 de janeiro de 1975), através do qual o Conselho Constitucional francês se declarou incompetente para analisar de forma preventiva a convencionalidade de determinada lei francesa em relação à Convenção Europeia de Direitos Humanos, pois, segundo seu entendimento, o Conselho somente teria competência para deliberar sobre controle de constitucionalidade (FEILKE, 2014). 


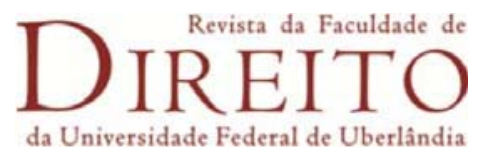

No que diz respeito ao âmbito relevante ao caso brasileiro ${ }^{18}$, é importante notar que a ideia de controle de convencionalidade das leis existe na Convenção Americana de Direitos Humanos desde a sua criação, mas o termo controle de convencionalidade propriamente dito só foi aparecer na atuação contenciosa da Corte Interamericana de Direitos Humanos recentemente, em 2006, no emblemático Caso Almonacid Arellano e outros Vs. Chile, considerado o caso que inaugura a doutrina do controle de convencionalidade no âmbito Americano e no qual a Corte disse:

A Corte tem consciência de que os juízes e tribunais interno estão sujeitos ao ímpeto da lei e, por isso, estão obrigados a aplicar as disposições vigentes no ordenamento jurídico. Porém, quando um Estado ratifica um tratado internacional como a Convenção Americana, seus juízes, como parte do aparato do Estado, também estão submetidos a ela, o que os obriga a velar para que os efeitos das disposições da Convenção não se vejam prejudicados pela aplicação de leis contrárias ao seu objeto e fim, e que desde o seu início carecem de efeitos jurídicos. Em outras palavras, o Poder Judiciário deve exercer uma espécie de controle de convencionalidade' entre as normas jurídicas internas que aplicam nos casos concretos e a Convenção Americana sobre Direitos Humanos. Nesta tarefa, o Poder Judiciário deve ter em conta não somente o tratado, senão também a interpretação que do mesmo tem feito a Corte Interamericana, intérprete última da Convenção Americana (apud MAZZUOLI, 2011, p. 85).

Relevante nesse trecho do julgamento é o comentário feito em relação aos precedentes da Corte, ou seja, o controle de convencionalidade não deve ser feito somente tomando em consideração a Convenção Americana, mas também a interpretação dada à Convenção pela sua intérprete autêntica, a Corte Interamericana. Ainda no mesmo ano, no Caso dos Trabalhadores Demitidos do Congresso vs. Peru, a Corte reforçou o seu entendimento e destacou a função ex officio do Poder Judiciário neste tema ${ }^{19}$ :

Quando um Estado ratifica um tratado internacional como a Convenção Americana, seus juízes também estão submetidos a ela,

\footnotetext{
${ }^{18}$ Importante notar que o Brasil ratificou a Convenção Americana de Direitos Humanos em 1992 e, através do Decreto Legislativo n. 89, desde 1998, submete-se à jurisdição da Corte Interamericana de Direitos Humanos.

19 É que, no mesmo sentido da existência de um bloco de constitucionalidade, todo o corpus jurisprudencial lato sensu da Corte Interamericana (e aqui inclui-se, também, as suas opiniões consultivas) forma um bloco de convencionalidade.
} 
o que os obriga a velar para que o efeito útil da Convenção não se veja diminuído ou anulado pela aplicação de leis contrárias às suas disposições, objeto e fim. Em outras palavras, os órgãos do Poder Judiciário devem exercer não somente um controle de constitucionalidade, senão também de convencionalidade ex officio entre as normas internas e a Convenção Americana (apud MAZZUOLI, 2011, p. 86).

Desta forma, percebe-se que os tratados internacionais de direitos humanos em vigor no Brasil - em conjunto com a Constituição Federal - são paradigma de controle da produção normativa doméstica (MAZZUOLI, 2011). A esse controle de compatibilização das leis internas com os tratados de direitos humanos dá-se o nome de controle de convencionalidade. ${ }^{20} \mathrm{Ou}$ seja, toda lei brasileira conflitante com o direito internacional dos direitos humanos (desde que internalizados pelo Brasil por meio de ratificação), seja anterior ou posterior ao tratado, é inválida. De acordo com Mazzuoli (2011, p. 133), "Trata-se de adaptar ou conformar os atos ou leis internas aos compromissos internacionais assumidos pelo Estado, que criam para estes deveres no plano internacional com reflexos práticos no plano do seu direito interno".

Portanto, de maneira sistematizada, o controle de convencionalidade é responsável por compatibilizar os tratados internacionais de direitos humanos vigentes no país com o direito doméstico. Esse controle pode ser realizado tanto de maneira difusa (para qualquer tratado de direitos humanos devidamente ratificado) como de forma concentrada (para aqueles tratados de direitos humanos que passarem pelo rito do parágrafo $3^{\circ}$ do artigo $5^{0}$ da Constituição). ${ }^{21}$

\footnotetext{
${ }^{20}$ Importante frisar, por relevante à análise do RE n. 511.961/2009 que será feita adiante, que o controle de convencionalidade pode ser realizado tanto com base nos precedentes contenciosos da Corte Interamericana como em relação à sua jurisdição consultiva.

${ }^{21}$ Partindo da premissa de que os tratados comuns (que não versam sobre direitos humanos) possuem status supralegal, é interessante citar a expressão controle de supralegalidade, criada por Valério Mazzuoli (2011), para determinar a compatibilização das leis com os tratados internacionais comuns que estão acima delas.
} 
5. Análise da decisão judicial sobre "a exigência de diploma de curso superior para o exercício da profissão de jornalista" (RE n. $511.961 / 2009)$

Feitas as considerações necessárias sobre o direito humano e fundamental à liberdade de expressão e sobre a teoria do controle de convencionalidade das leis, far-se-á, neste momento, uma análise da decisão judicial sobre "a exigência de diploma de curso superior para o exercício da profissão de jornalista" (RE n. 511. 961/2009), a fim de demonstrar que, neste julgamento, o STF se utilizou da Convenção Americana e, também, da opinião consultiva da Corte Interamericana de Direitos Humanos para ressalvar o direito à liberdade de expressão em detrimento à legislação interna, promovendo verdadeiro controle de convencionalidade.

Tratou-se o caso de Recurso Extraordinário, interposto pelo Ministério Público Federal (MPF) e pelo Sindicato das Empresas de Rádio e Televisão do Estado de São Paulo (SERTESP), na qualidade de assistente simples, contra acordão do Tribunal Regional Federal da $3^{\text {a }}$ Região que, nos autos da ação civil pública de $\mathrm{n}^{\mathrm{o}}$ 2001.61.00.025946-3, modificou o entendimento de $1^{\mathrm{a}}$ instância. O MPF visou, com a referida ação civil pública, um pronunciamento judicial reconhecendo a não-recepção, pela Constituição Federal de 1988 (em face de seus artigos $5^{\circ}$, IX e XIII, e 220, caput e $\S 1^{\circ}$ ), do artigo $4^{\circ}$, inciso V, do Decreto-Lei de $\mathrm{n}^{\circ} 972$ de 1969.

Em síntese, defendeu o MPF que não pode o legislador infraconstitucional estabelecer condições para o exercício profissional impondo restrições indevidas e não razoáveis, como seria o caso da exigência de diploma de curso superior de jornalismo prevista no do artigo $4^{\circ}$, inciso $\mathrm{V}$, do Decreto-Lei de $n^{0} 972$ de 1969. Ademais, alegou, também, que tal dispositivo legal violaria o artigo 13 da Convenção Americana de Direitos Humanos (direito à liberdade de expressão), ratificada pelo Brasil em 1992. Ao final, argumentou que, independentemente do entendimento do STF quanto ao status do Pacto de San José da Costa Rica (se lei ordinária, se 
supralegal ou constitucional), o artigo $4^{\circ}$, inciso V, do Decreto-Lei de $\mathrm{n}^{\circ} 972$ de 1969 teria siso revogado pelo Pacto. Conforme enfatizado pelo Ministro Gilmar Mendes no voto de relatoria:

Desde que foi posta no juízo de primeira instância ( $16^{\text {a }}$ Vara Cível
Federal de São Paulo), essa questão tem sido discutida de acordo
com duas perspectivas de análise. A primeira enfatiza o aspecto
relacional-comparativo entre o Decreto-Lei n ${ }^{\circ} 972 / 1969$ e a
Constituição de 1988, especificamente em relação às liberdades de
profissão, de expressão e de informação protegidas pelos artigos $5^{\circ}$,
IX e XIII, e 220. A segunda questiona o referido decreto-lei em face
do art. 13 (liberdade de expressão) da Convenção Americana de
Direitos Humanos, denominado Pacto de San José da Costa Rica,
ao qual o Brasil aderiu em 1992 .

As opiniões emitidas pelos Ministros do STF quando do julgamento deste RE n. 511.961/2009 são brilhantes (em especial o voto do relator, Ministro Gilmar Mendes) e dariam ensejo à discussão de diversos - e relevantes - temas (tais como o princípio da proporcionalidade, a questão do conteúdo essencial dos direitos humanos, etc). Contudo, para os fins propostos neste trabalho, ater-se-á somente à questão da argumentação no julgamento referente à Convenção Americana, por ser a única pertinente ao tema aqui tratado, qual seja: controle de convencionalidade.

Para concluir pela não-recepção do artigo $4^{\circ}$, inciso V, do Decreto-Lei de $n^{\circ} 972$ de 1969 pela Constituição Federal de 1988 o Ministro Gilmar Mendes, em seu voto de relatoria, fundamentou a sua decisão no que o próprio Ministro classificou como "[...] entendimento consolidado no âmbito do sistema interamericano de direitos humanos". De fato, boa parte da fundamentação do voto relator foi baseada na Opinião Consultiva $n^{\circ} 5$, de 13 de novembro de 1985, da Corte Interamericana de Direito Humanos (o Caso La colegiación obligatoria de periodistas) e no entendimento da Organização dos Estados Americanos (OEA) sobre o tema.

O Caso La colegiación obligatoria de periodistas foi um caso de opinião consultiva solicitado à Corte Interamericana pelo Governo da Costa Rica, no sentido de demandar a opinião da Corte sobre a interpretação dos artigos 13 e 39 da Convenção Americana em relação à obrigatoriedade de 
inscrição em conselho profissional de jornalistas (no caso, o Colegio de Periodistas) e de apresentação de título universitário para o exercício da profissão jornalística. Segundo o voto do Ministro Gilmar Mendes:

A Corte Interamericana de Direitos Humanos proferiu decisão no dia 13 de novembro de 1985, declarando que a obrigatoriedade do diploma universitário e da inscricão em ordem profissional para o exercício da profissão de jornalista viola o art. 13 da Convenc,ão Americana de Direitos Humanos, que protege a liberdade de expressão em sentido amplo.

Já a fundamentação baseada no entendimento da OEA, através da Comissão Interamericana de Direitos Humanos, teve como suporte o Informe Anual da referida Comissão, de 25 de fevereiro de 2009, que defendeu que - nas palavras do Ministro Gilmar Mentes "[...] tem defendido que a exigência de diploma universitário em jornalismo como condicãa obrigatória para o exercício dessa profissão viola o direito à liberdade de expressão".

Nesse mesmo sentido e acompanhando o voto do relator, foram os votos da Ministra Cármen Lúcia e do Ministro Ricardo Lewandowski, os quais citaram, para acompanhar o voto do relator, a incompatibilidade do artigo $4^{\circ}$, inciso V, do Decreto-Lei de $\mathrm{n}^{\circ} 972$ de 1969 com a Convenção Americana. De acordo com o voto da Ministra Cármen Lúcia:

Não tenho dúvida nenhuma em que, tanto material quanto formalmente, não há recepção do Decreto-Lei no 972 pela Constituição de 88. Eu poderia afirmar e tenho como fundamento exatamente como posto por Vossa Excelência; não há razão de ser juridicamente aceitável, constitucionalmente aceitável, em face do que dispõem os incisos IV, IX e XIII da Constituição; não há critério de proporcionalidade possível de ser acolhido, eu acho, em face do sistema constitucional brasileiro, a fixação do artigo $4 \mathrm{a}$, no seu inciso $\mathrm{V}$, do decreto-lei, e não há também possibilidade de compatibilizá-lo com o artigo 13 da Convenção do Tratado de São José da Costa Rica. [grifo nosso]

Como dito, no mesmo sentido, o voto do Ministro Ricardo Lewandowski, citando o parecer de 21 de fevereiro de 1992 de Geraldo Ataliba: 
A plena liberdade de expressão do pensamento, isenta de quaisquer restrições ou empecilhos de caráter legal ou burocrático, que encontra abrigo na nova ordem constitucional, mostra-se, ademais, inteiramente consentânea com os tratados internacionais de proteção dos direitos humanos, em especial com o Pacto de San José da Costa Rica, internalizado pelo Decreto $n^{\circ}$ 678/1992 - e que integra o património dos direitos implícitos da cidadania, a teor do $\S 2^{\circ}$ do art. $5^{o}$ da Constituição, o qual, em seu art. 13.3, significativamente, consigna que: "não se pode restringir o direito de expressão por vias ou meios indiretos, tais como abuso de controles oficiais, ou particulares de papel de imprensa, de frequências radioelétricas ou de equipamentos e aparelhos usados na difusão da informação, nem por quaisquer outros meios destinados a obstar a comunicação e a circulação de ideias e opiniões. [grifo nosso]

Por maioria de votos (7 a 1), ao final do julgamento, o artigo $4^{\circ}$, inciso V, do Decreto-Lei de $\mathrm{n}^{\circ} 972$ de 1969 foi declarado não-recepcionado pela Constituição de 1988, sendo o Ministro Marco Aurélio o único voto vencido. Percebe-se, neste caso, que se decidiu pela liberdade de expressão enquanto direito humano e fundamental com posição preferencial, nos termos do artigo 13 do Pacto de San José da Costa Rica.

A decisão do RE 511.961 de 2009 nos leva a duas grandes conclusões a cerca do tema desta pesquisa: primeiramente, o fato de o Ministro Gilmar Mendes, na qualidade de relator do processo, ter fundamentado boa parte da sua decisão na Convenção Americana de Direitos Humanos (artigo 13) e, também, na interpretação do referido artigo pela Corte Interamericana de Direitos Humanos demonstra que a jurisprudência do STF, malgrado ainda sustentar o posicionamento retrógrado de que os tratados de direitos humanos possuem status supralegal, tem evoluído no sentido de se utilizar de tais tratados para interpretar a legislação interna, efetuando verdadeiro controle de convencionalidade, o que, até pouco tempo, não era sequer admitido pela nossa Corte Suprema.

Contudo, a segunda conclusão a que se chega é a de que, infelizmente, apesar de ter evoluído, a jurisprudência do STF não tem evoluído o suficiente no que tange ao tema controle de convencionalidade. Isso pode ser facilmente percebido na falta de qualquer menção à Convenção Americana 
ou ao entendimento da Corte Interamericana em 4 dos votos que seguiram o entendimento do relator (a saber: Ministros Eros Grau, Carlos Britto, Cezar Peluso e Ministra Ellen Gracie). Tal argumento fica ainda mais fortemente evidenciado quando, em seu voto, o Ministro Marco Aurélio se sentiu à vontade para discordar do voto relator sem, também, fazer qualquer alusão, ainda que mínima, à Convenção Americana ou ao entendimento da Corte Interamericana, demonstrando total desapreço com a ampla argumentação feita sobre o tema no voto de relatoria.

\section{Conclusão}

A evolução dos direitos humanos é um processo contínuo de busca da valorização e reconhecimento de tais direitos dentro dos âmbitos internos estatais. Atualmente e em compatibilização com o nível contemporâneo de desenvolvimento dos direitos humanos, superou-se a visão de que a soberania estatal não pode ser mitigada e se verifica cada vez mais a adesão de Estados a mecanismos internacionais judiciais, promovendo uma maior integração entre o sistema normativo internacional e o nacional. Nesse mesmo sentido, os Estados passaram a aceitar e a se submeter à jurisdição internacional e, em paralelo, passaram a ter o seu direito interno condicionado por estas normas internacional de direitos humanos.

O Estado brasileiro, de cunho reconhecidamente humanitário, assinou e ratificou -praticamente - todos os tratados, acordos e convenções internacionais de direitos humanos hoje existentes, tendo, inclusive, se submetido à jurisdição internacional da Corte Interamericana de Justiça e do Tribunal Penal Internacional. Nesse sentido se insere o debate sobre o controle de convencionalidade das leis como verdadeiro mecanismo de compatibilização da norma interna brasileira em consonância com as normas internacionais de direitos humanos recepcionadas pelo Estado brasileiro. 
Defendeu-se, neste estudo - contrariamente ao atual posicionamento do STF - que, por força do $§ 2^{\circ}$ do artigo $5^{\circ}$ da Constituição Federal de 1988, os direitos e garantias individuais internacionalmente consagrados (notadamente aqueles trazidos ao direito interno por meio de tratados internacionais de direitos humanos devidamente ratificados pelo Brasil) possuem nível constitucional, aplicação imediata e passam a compor o bloco de constitucionalidade brasileiro, servindo, portanto, de paradigma de controle da produção normativa doméstica.

Nesse sentido, a análise da decisão judicial sobre "a exigência de diploma de curso superior para o exercício da profissão de jornalista" (RE n. 511.961/2009), e em especial do voto de relatoria do Ministro Gilmar Mendes, demonstra claramente que o STF praticou - acertadamente verdadeiro controle de convencionalidade ao declarar que, em razão de incompatibilidade com o artigo 13 da Convenção Americana, o artigo $4^{\circ}$, inciso V, do Decreto-Lei de $n^{\circ} 972$ de 1969 não foi recepcionado pela ordem constitucional vigente. Nesse julgamento, o STF deixou claro o seu entendimento sobre o direito humano fundamental à liberdade de expressão, colocando-o em posição de superioridade (preferred right).

Conforme demonstrado na análise feita acima, é possível perceber que o Estado brasileiro anuncia o início de um movimento de engajamento de compatibilização da sua legislação interna com as normas de direitos humanos, notadamente através das decisões judiciais (controle de convencionalidade), demonstrado que pretende ir além da sua obrigação de observar as normas internacionais a que se submeteu no âmbito externo.

Contudo, a mesma análise que indica um progresso na utilização da teoria do controle de convencionalidade das leis no âmbito do Poder Judiciário indica, também, que essa evolução é ainda muito lenta no Estado brasileiro. De fato, 4 dos votos que seguiram o entendimento do relator (a saber: Ministros Eros Grau, Carlos Britto, Cezar Peluso e Ministra Ellen Gracie) e, do mesmo modo, o voto do Ministro Marco Aurélio, não fizeram 


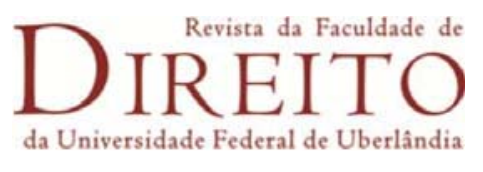

qualquer alusão, ainda que mínima, à Convenção Americana (artigo 13) ou ao entendimento da Corte Interamericana (Opinião Consultiva $\mathrm{n}^{0} 5$ de 1985), demonstrando total desapreço com a ampla argumentação feita sobre o tema no brilhante voto de relatoria do Ministro Gilmar Mendes.

Portanto, defende-se aqui a ampla utilização do controle de convencionalidade das leis pelo Poder Judiciário brasileiro como forma de afastar, definitivamente, qualquer tentativa ou forma de mitigação dos direitos humanos, tal como foi feito no julgamento do RE n. 511.961/2009, o qual respeitou a importância dada ao direito humano e fundamental à liberdade de expressão na Convenção Americana.

\section{Referências}

BARCELLOS, Ana Paula. Neoconstitucionalismo, direitos fundamentais e controle de políticas públicas. In: SARMENTO, Daniel. GALDINO, Flávio. (Orgs.) Direitos fundamentais: estudos em homenagem ao professor Ricardo Lobo Torres. Rio de Janeiro: Renovar, 2006. p. 31-60.

BARROSO, Luís Roberto. Colisão entre Liberdade de Expressão e Direitos da Personalidade. Critérios de Ponderação. Interpretação Constitucionalmente adequada do Código Civil e da Lei de Imprensa. Revista de Direito Administrativo da FGV, Rio de Janeiro. n. 235. p. 1-36. Jan/mar 2004.

BONAVIDES, Paulo. Curso de direito constitucional. $7^{a}$ Edição. São Paulo: Editora Malheiros, 1997.

2006.

Curso de direito constitucional. 19a Edição. São Paulo: Editora Malheiros,

BRASIL. Constituição (1988). Constituição da República Federativa do Brasil. Brasília, DF: Senado Federal: Centro Gráfico, 1988.

CAMPOS, Thiago Yukio Guenka; BASTOS JUNIOR, Luiz Magno Pinto. Para além do debate em torno da hierarquia dos tratados: do duplo controle vertical das normas internas em razão da incorporação dos tratados de direitos humanos. RFD- Revista da Faculdade de Direito da UERJ, v.1, n. 19, jun./dez 2011.

CEIA, Eleonora Mesquita. A Jurisprudência da Corte Interamericana de Direitos Humanos e o desenvolvimento da proteção dos Direitos Humanos no Brasil. Revista EMERJ, Rio de Janeiro, v. 16, n. 61, jan-fev-mar. 2013.

CORREIA, Theresa Rachel Couto. Considerações iniciais sobre o conceito de direitos humanos. Pensar - Revista de Ciências Jurídicas, Fortaleza, v. 10, n. 10, fev. 2005. Disponível em: < https://periodicos.unifor.br/rpen/article/view/767/1629>. Acesso em: 28 mai. 2016.

DIMOULIS, Dimitri; MARTINS, Leonardo. Teoria Geral dos Direitos Fundamentais. São Paulo: Editora Revista dos Tribunais, 2007. 


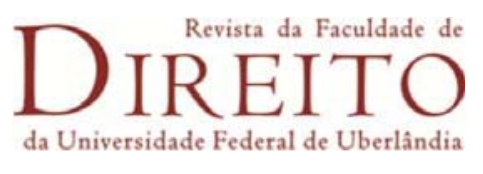

FEILKE, Pedro Ribeiro Agustoni. O controle de convencionalidade e a jurisprudencia do Supremo Tribunal Federal. Revista Direito em Debate. v. 23, n. 41, p. 147-186, 9 dez. 2013.

GARCIA, Maria. Mas, quais são os direitos fundamentais? Revista de Direito Constitucional e Internacional, São Paulo, n. 39, p. 115-123, 2002.

GOYARD-FABRE, Simone. O que é democracia? A genealogia filosófica de uma grande aventura humana. Tradução: Claudia Berliner. São Paulo: Martins Fontes, 2003.

GRIMM, Dieter. Freedom of speech in a globalized world. In: HARE, Ivan; WEISTEIN, James. Extreme speech and democracy. Oxford: Oxford University, 2009. p. 11-22.

GUERRA FILHO, Wilis Santiago. Autopoiese do direito na sociedade pós-moderna: introdução a uma teoria social sistêmica. Porto Alegre: Livraria do Advogado, 1997.

HELD, David. Modelos de democracia. Tradução: Alexandre Sobreira Martins. Belo Horizonte: Paidéia, 1996.

LEVIN, Abigail. The cost of free speech: pornography, hate speech, and their challenge to liberalism. Nova Iorque/Hampshire: Palgrave Macmillan, 2010.

LOPES, Ana Maria D'Ávila. Hierarquização dos direitos fundamentais? Revista de Direito Constitucional e Internacional, São Paulo, n. 34, p. 168-163, 2001.

Os direitos fundamentais como limites ao poder de legislar. Porto Alegre: Sergio Antonio Fabris Editor, 2001b.

Bloco de constitucionalidade e princípios constitucionais: desafios do poder judiciário. Revista Sequência, nº 59, p. 43-60, dez. 2009.

Disciplina de Direitos e Garantias fundamentais: programa de pósgraduação em Direito Constitucional da Universidade de Fortaleza. Notas de Aula. fev. 2016 a mai. 2016.

MACHADO, Jónatas. Liberdade de expressão: dimensões constitucionais da esfera pública no sistema social. Coimbra: Coimbra, 2002.

MARMELSTEIN, George. Curso de direitos fundamentais. São Paulo: Altas, 2008.

MAUÉS, Antonio Moreira. Supralegalidade dos tratados internacionais de direitos humanos e interpretação constitucional. In: LOPES, Ana Maria D’Ávila; MAUÉS, Antonio Moreira (Orgs.). Eficácia nacional e internacional dos direitos humanos. Rio de Janeiro: Lumen Juris, 2013, p. 27-50.

MAZZUOLI, Valério de Oliveira. O controle jurisdicional da convencionalidade das leis. 2. ed. rev. atual. e ampl. São Paulo: Editora Revista dos Tribunais, 2011. (Coleção direito e ciências afins; v. 4 - Coordenação Alice Bianchini, Luiz Flávio Gomes e William Terra de Oliveira).

MELLO, Celso Duviver de Albuquerque. $\mathrm{O} \S 2^{\circ}$ do art. $5^{\circ}$ da Constituição Federal. In: TORRES, Ricardo Lobo (org.). Teoria dos Direitos Fundamentais. Rio de Janeiro: Renovar, 1999.

MENDES, Gilmar Ferreira. A Jurisdicão constitucional no Brasil e seu significado para a liberdade e a igualdade. Palestra proferida em 18.11.2008, na Faculdade de Direito da Universidade de Wilhelms. 2008. Disponível em: http://www.stf.jus.br/arquivo/cms/noticiaArtigoDiscurso/anexo/munster_port.pdf. Acesso em: 28 mai. 2016.

MEYER-PFLUG, Samantha Ribeiro. Liberdade de expressão e discurso do ódio. São Paulo: Revista dos Tribunais, 2009. 


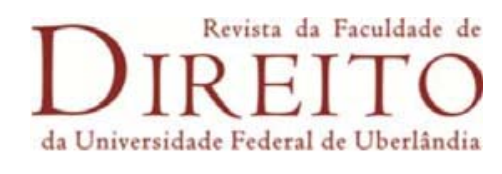

MILL, John Stuart. On liberty. Indianápolis: Hackett, 1978.

PIOVESAN, Flávia. Direitos humanos e o direito constitucional internacional. $8^{\mathrm{a}}$ ed. ver. ampl. e atual. São Paulo: Saraiva, 2007.

RAMOS, André de Carvalho. Supremo Tribunal Federal brasileiro e o controle de convencionalidade: levando a sério os tratados de direitos humanos. Revista da Faculdade de Direito da Universidade de São Paulo. v. 104. p. 241 - 286. jan./dez. 2009.

RUIZ, Thiago. O direito à liberdade: uma visão sobre a perspectiva dos direitos fundamentais. Revista de Direito Público, Londrina, v. 1, n. 2, p. 137-150, mai./ago. 2006.

SARLET, Ingo Wolfgang. A Eficácia dos Direitos Fundamentais. $8^{a}$ Edição, Porto Alegre: Livraria do Advogado Ed., 2007.

TRINDADE, Antonio Augusto Cançado. Tratado de direito internacional dos direitos humanos. Vol. I. $2^{\mathrm{a}}$ ed. Porto Alegre: Sérgio Antonio Fabris, 2003a.

Tratado de direito internacional dos direitos humanos. Vol. III. $2^{\mathrm{a}}$ ed. Porto Alegre: Sérgio Antonio Fabris, 2003b.

Desafios e conquistas do direito internacional dos direitos humanos no início do século XXI. In: CACHAPUZ DE MEDEIROS, Antônio Paulo (org.). Desafios do direito internacional contemporâneo. Brasília: Fundação Alexandre Gusmão, 2007.

International law for humankind: towards a new jus gentium. 2. ed. Leiden: Martinus Nijhoff Publishers, 2012.

Artigo recebido em: 02/09/2019.

Aceito para publicação em: 30/04/2020. 